\title{
Antigenic and genotypic characterization of rabies virus isolated from bats (Mammalia: Chiroptera) from municipalities in São Paulo State, Southeastern Brazil
}

\author{
Benedito Donizete Menozzi ${ }^{1} \cdot$ Rafael de Novaes Oliveira $^{2} \cdot$ Laís Moraes Paiz $^{3}$. \\ Virgínia Bodelão Richini-Pereira ${ }^{4} \cdot$ Helio Langoni $^{1}$
}

Received: 27 July 2016/Accepted: 22 December 2016/Published online: 20 January 2017

(C) Springer-Verlag Wien 2017

\begin{abstract}
Bats have aroused growing attention in the public health sphere because they are considered the main reservoir of rabies virus (RABV) in the Americas, in places where canine rabies is under control. Antigenic and genetic studies of RABV isolates have been used to describe the epidemiological profile of rabies and to identify possible hosts/reservoirs for different epidemiological cycles. This study describes the antigenic and genotypic characterization of 19 RABV isolates from central nervous system samples of non-hematophagous bats (Mammalia: Chiroptera). These bats were diagnosed as RABV positive by direct fluorescent antibody and mouse inoculation tests.
\end{abstract}

Nucleotide sequence data reported are available in the GenBank database under the accession numbers KX531062 (105/08), KX531063 (122/09), KX531064 (169/06), KX531065 (180/05), KX531066 (204/09), KX531067 (206/07), KX531068 (211/08), KX531069 (233/03), KX531070 (24/10), KX531071 (245/06), KX531072 (274/04), KX531073 (291/06), KX531074 (320/06), KX531075 (394/06), KX531076 (419/05) and KX531077 (691/06). Identification numbers are shown in parentheses after each accession number.

Helio Langoni

hlangoni@fmvz.unesp.br

1 Department of Veterinary Medicine and Public Health, School of Veterinary Medicine and Animal Science, São Paulo State University (UNESP), Rubião Jr. District, Botucatu, São Paulo 18618-970, Brazil

2 Pasteur Institute, 393 Paulista Ave., São Paulo, São Paulo 01311-000, Brazil

3 Department of Public Health, School of Medical Sciences, State University of Campinas, 126 Tessália Vieira de Camargo St., Campinas, São Paulo 13083-887, Brazil

4 Adolfo Lutz Institute, Bauru II Center of Regional Laboratories, 6000 Rubens Arruda St., Bauru, São Paulo 17015-110, Brazil
Antigenic characterization using a panel of eight monoclonal antibodies revealed that 7 of 19 RABV isolates from these bats belonged to variant 3 , for which the hematophagous bat species Desmodus rotundus is the main reservoir, and 1 of $19 \mathrm{RABV}$ isolates from an insectivorous bat belonged to variant 4 , which is characteristic of these bats. The remaining 11 RABV samples were divided into six non-compatible profiles. The isolates were subjected to reverse transcription polymerase chain reaction for the $N$ gene and partially sequenced. Genetic characterization of these isolates was performed by grouping the sequences obtained with known RABV lineages. The sequences were grouped in clusters by the phylogenetic inference neighborjoining method, together with another 89 homologous sequences obtained from GenBank. This analysis grouped the isolates into four known lineages: Nyctinomops Brazil, Myotis Brazil, Eptesicus Brazil and D. rotundus Brazil, as well as another cluster that may define a RABV lineage not yet characterized, here named Myotis Brazil II, for which bats of the genus Myotis apparently act as reservoirs. This assumption of a new lineage is also based on the observation of amino acid substitutions, with an average intraspecific identity of $99.8 \%$, varying from 99.6 to $100.0 \%$ for nucleotides and $100.0 \%$ for amino acids.

\section{Introduction}

Rabies is a fatal viral infectious disease that affects the central nervous system (CNS) and which predominantly affects mammals. It is distributed worldwide, with about 40,000 to 70,000 human deaths per year, almost all of them in developing countries, especially in Asia and Africa [1]. 
The disease is caused by rabies virus (RABV), an RNA virus that belongs to the order Mononegavirales, family Rhabdoviridae, and genus Lyssavirus. The virus has a negative-sense ( $\left.3^{\prime}-5^{\prime}\right)$, single-strand and non-segmented RNA genome. It is 100 to $250 \mathrm{~nm}$ long and $75 \mathrm{~nm}$ in diameter and has a 11,932-nucleotide genome that encodes five structural proteins: $\mathrm{N}$ (nucleoprotein), $\mathrm{P}$ (phosphoprotein), M (matrix protein), G (glycoprotein) and L (RNA polymerase) [2].

In terms of amino acid sequence similarity, the $\mathrm{N}$ protein is the most conserved among members of the genus Lyssavirus, although a relatively high degree of genetic diversity is found in some small regions of the $\mathrm{N}$ gene in the different genotypes. For this reason, for detection of RABV by reverse transcription polymerase chain reaction (RT-PCR), the gene encoding the $\mathrm{N}$ protein is the one that is most commonly used [2]. Fourteen species can be distinguished by sequencing this gene [3].

Molecular studies of RABV have shown that there are many reservoirs for this genotype. These different reservoirs play a fundamental role in the specific maintenance of each viral variant in the environment [4-7].

Sylvatic rabies has grown in importance due to the synanthropic habits of bats and other wild mammals, which began to inhabit urban and transitional areas as a consequence of the greater availability of food and the environmental impact of anthropogenic changes in their habitat [8].

Thus, a large increase has occurred in the bat populations of urban centers due to a lack of planning, especially concerning the creation of architectural and landscape projects [9]. Following this increase, epidemiological surveillance was intensified, which resulted in an increase in positive diagnoses of RABV infections in bats, indicating that the virus was circulating even in areas where the disease was considered under control [10]. According to the Brazilian Health Ministry, until 2003, cases of human rabies involved dogs as the main source of transmission, but from 2004 onward, bats assumed this role [11].

Antigenic and genetic studies of RABV isolates in Latin America have been used to determine the epidemiological profile of rabies and to identify possible hosts and reservoirs involved in different epidemiological cycles of the disease. Understanding the evolution of RABV is fundamental for determining the phenotypic and genotypic variability of the viral population. Monitoring the appearance of viral variants in new hosts and their ability to change is important in the development of new vaccines. Moreover, it is known that minor mutations in certain regions of the genome, sometimes of only one amino acid, can modify the pathogenicity and virulence of RABV [12].

Despite scientific and technological advances, rabies is still a big challenge for public health [13]. Recently, our knowledge concerning rabies epidemiology has made advances, particularly due to the molecular characterization of viral isolates, which, among other aspects, enables the determination of the geographic distribution of RABV variants and the identification of reservoir species [5]. The application of genetic analysis methods has revealed that, despite antigenic differences, RABV isolates that adapt to different species show changes in a conserved gene that can be used as epidemiological markers [14].

Therefore, antigenic and genetic characterization is fundamental for investigating the endemic cycles of RABV and its potential for inter-species transmission. The coexistence of a varied population of bats, humans and domestic animals in urban centers makes it essential to understand the epidemiology of RABV in areas where the pattern of viral circulation is unknown.

Thus, we conducted a study to genetically and antigenically characterize 19 samples of RABV isolated from non-hematophagous bats from five cities of São Paulo State, Brazil, in order to determine the molecular epidemiology of the virus in these animals and in the region studied.

\section{Materials and methods}

\section{RABV isolates}

We conducted a study of 19 RABV isolates from the CNS of non-hematophagous bats. The isolates were obtained by first and second passages in mice inoculated with CNS material from bats of the following genera/species: four Artibeus lituratus, four Artibeus spp.; two Myotis nigricans, four Myotis spp.; four Molossus spp. and one Nyctinomops spp. (Table 1).

These bats were sent to the Zoonosis Diagnostic Laboratory of São Paulo State University (UNESP), located in the municipality of Botucatu, SP, Brazil (where isolation was performed) as part of the rabies epidemiological surveillance activities performed by municipal administrations in the region. Bats were found dying or dead in homes or streets from 2003 to 2010 in the municipality of Botucatu (14 specimens) and in four other municipalities nearby: Bauru (1), São Manuel (1), Dois Córregos (1) and Piratininga (2) (Table 1).

The identification and classification (genus/species) of the bats studied was performed using the taxonomic keys of Vizotto and Taddei [15] and Gregorin and Taddei [16]. All of the samples from which virus was isolated had previously tested positive by a direct fluorescent antibody (DFA) test, described by Dean et al. [17], and a mouse inoculation test (MIT), described by Koprowski [18]. 
Table 1 Epidemiological information on the 19 rabies virus isolates from central nervous samples of nonhematophagous bats and antigenic typing of the isolates using a panel of eight monoclonal antibodies produced by the Centers for Disease Control and Prevention (Atlanta, USA)

\begin{tabular}{lllll}
\hline Sample & Year of examination & Genus/species & Municipality & Antigenic profile \\
\hline 233 & 2003 & Artibeus lituratus & Botucatu & AgV-3 \\
274 & 2004 & Molossus spp. & Botucatu & AgV-3 \\
180 & 2005 & Molossus spp. & Botucatu & NC1* C4 C10 C12 \\
419 & 2005 & Artibeus spp. & Botucatu & AgV-3 \\
169 & 2006 & Molossus spp. & Bauru & NC1* C4 C10 C12 \\
245 & 2006 & Artibeus lituratus & Botucatu & AgV-3 \\
291 & 2006 & Artibeus spp. & Botucatu & AgV-3 \\
320 & 2006 & Artibeus spp. & Botucatu & AgV-3 \\
394 & 2006 & Myotis spp. & São Manuel & NC5* C1 C9 C15 \\
691 & 2006 & Myotis spp. & Botucatu & NC2* - C9 C10 C12 \\
096 & 2007 & Nyctinomops spp. & Botucatu & NC4* - C10 C12 \\
206 & 2007 & Artibeus spp. & Botucatu & AgV-3 \\
105 & 2008 & Molossus spp. & Dois Córregos & NC3* C9 C10 \\
205 & 2008 & Myotis spp. & Piratininga & NC1*- C4 C10 C12 \\
211 & 2008 & Myotis spp. & Piratininga & AgV-4 \\
122 & 2009 & Artibeus lituratus & Botucatu & NC1* C4 C10 C12 \\
204 & 2009 & Artibeus lituratus & Botucatu & NC2* C9 C10 C12 \\
024 & 2010 & Myotis nigricans & Botucatu & NC2* C9 C10 C12 \\
063 & 2010 & Myotis nigricans & Botucatu & NC6* C4 C9 C12 \\
\hline
\end{tabular}

* NC: non-compatible
The fixed rabies virus sample or CVS (challenge virus standard) was maintained by intracerebral passages in mice and was used as a positive control in the DFA reaction and RT-PCR. This study was approved by the Animal Experimentation Ethics Committee of the Botucatu Medical School of UNESP under protocol no. 762/2009.

\section{Antigenic characterization}

Antigenic analysis was performed according to a protocol described by Diaz et al. [19] by the indirect immunofluorescence technique, using samples of mouse CNS tissue infected with RABV and a panel of eight monoclonal antibodies (MAbs) against the $\mathrm{N}$ protein of RABV [20]. This panel is capable of identifying eleven distinct variants based on their distinct reactivity patterns (Table 2). The panel was produced by the Centers of Disease Control and Prevention (CDC) in Atlanta, USA, and provided by the Pan-American Health Organization.

\section{RT-PCR and DNA sequencing}

Total RNA was extracted from the 19 mouse CNS isolates of RABV that were positive by the MIT technique, as well as the positive and negative controls, using the TRIzol method (Invitrogen, Carlsbad, CA, USA) according to the manufacturer's instructions. The controls used were a suspension of CNS from CVS-inoculated mice (positive control) and DNase and RNase-free ultrapure water (negative control). They were used from the phase of RNA extraction up to the amplification.

RT-PCR was performed using the extracted RNA from mouse CNS isolates of RABV according to the protocol standardized at the Molecular Biology Laboratory of the Pasteur Institute in São Paulo, SP. The PCR for partial amplification of the $N$ gene was conducted according to the protocol described by Orciari et al. [21] and Oliveira et al. [6], using the specific primers described in Table 3. These reactions were performed using the following conditions: initial denaturation at $94{ }^{\circ} \mathrm{C}$ for $5 \mathrm{~min}, 35$ cycles at $94{ }^{\circ} \mathrm{C}$ for $45 \mathrm{~s}, 35$ annealing cycles at $55^{\circ} \mathrm{C}$ for $45 \mathrm{~s}, 35$ extension cycles at $72{ }^{\circ} \mathrm{C}$ for $2 \mathrm{~min}$, and a final extension at $72{ }^{\circ} \mathrm{C}$ for $10 \mathrm{~min}$. RT-PCR for amplification of the $N$ gene was performed according to the protocol described by Orciari et al. [21] using primers $21 \mathrm{G}$ (forward) and 304 (reverse) (Table 2), performing the RT at $42{ }^{\circ} \mathrm{C}$ for $60 \mathrm{~min}$.

PCR products were subjected to $1 \%$ agarose gel electrophoresis and visually compared to a low-mass DNA ladder (Invitrogen, Carlsbad, CA, USA). The isolates that yielded products of 1478 base pairs (bp) for the $N$ gene were considered positive. PCR products were purified directly from PCR reaction products using a QIAquick Gel Extraction Kit (QIAGEN, The Netherlands) according to the manufacturer's instructions. Reactions that produced nonspecific bands were purified from the gel band using the 
Table 2 Profiles of reactions obtained with the panel of monoclonal antibodies (MAbs) produced by the Centers for Disease Control and Prevention (CDC) in Atlanta, USA, to characterize antigenic variants of rabies virus found in Latin America [20]

\begin{tabular}{llllllllll}
\hline Reservoir & $\mathrm{C} 1$ & $\mathrm{C} 4$ & $\mathrm{C} 9$ & $\mathrm{C} 10$ & $\mathrm{C} 12$ & $\mathrm{C} 15$ & $\mathrm{C} 18$ & $\mathrm{C} 19$ & $\mathrm{AgV}$ \\
\hline CVS/ERASAD/Past & + & + & + & + & + & + & + & + & Laboratory strain \\
Dog/mongoose & + & + & + & + & + & + & - & + & 1 \\
Dog & + & + & - & + & + & + & - & + & 2 \\
Desmodus rotundus & - & + & + & + & + & - & - & + & 3 \\
Tadarida brasiliensis & - & + & + & + & + & - & - & - & 4 \\
Desmodus rotundus Venezuela & - & + & + & + & + & $\mathrm{v}$ & - & $\mathrm{v}$ & 5 \\
Lasiurus cinereus & $\mathrm{v}$ & + & + & + & + & - & - & - & 6 \\
Arizona fox & + & + & + & - & + & + & - & + & 7 \\
Striped skunk Center/South USA & - & + & + & + & + & + & + & + & 8 \\
Tadarida braziliensis Mexico & + & + & + & + & + & - & - & - & 9 \\
Striped skunk California/Mexico & + & + & + & + & - & + & - & + & 10 \\
Desmodus rotundus Mexico & - & + & + & + & - & - & - & + & 11
\end{tabular}

$\mathrm{AgV}$, antigenic variant; + , positive reaction; -, negative reaction; $\mathrm{v}$, variable reactivity

Table 3 Primers used in reverse transcription polymerase chain reaction (RT-PCR) and DNA sequencing of the $N$ gene of rabies virus samples isolated from non-hematophagous bats

\begin{tabular}{lllll}
\hline Primer & Sense & Sequence & Use & Position in PV* sample \\
\hline $21 \mathrm{~g}$ & Forward & 5' ATGTAACACCTCTACAATG 3' & RT-PCR/ ${ }^{\text {a Seq }}$ & 55-73 \\
304 & Reverse & 5'TTGACGAAGATCTTGCTCAT 3' & RT-PCR/ ${ }^{\text {'Seq }}$ & 1514-1533 \\
P784 & Reverse & 5'CCTCAAAGTTCTTGTGGAAGA 3' & Sequencing & $779-799$
\end{tabular}

* PV sample, Pasteur virus strain (GenBank accession number M13215); ${ }^{\mathrm{a}} \mathrm{Seq}$, sequencing

same kit. After purification, DNA samples were visually quantified by $2 \%$ agarose gel electrophoresis using the ladder described above.

The DNA sequencing reaction consisted of $4.0 \mu \mathrm{L}$ of BigDye 3.1 (Applied Biosystems, Carlsbad, CA, USA), 3.2 pmol of forward primers $(21 \mathrm{G})$ and reverse primers (P784 and 304) in separate reactions, 5.0 to $20.0 \mathrm{ng}$ of DNA and DNA q.s.p. free water in a final reaction volume of $10 \mu \mathrm{L}$. The reactions were performed in a Mastercycler gradient thermocycler (Eppendorf, NY, USA) with 35 cycles of $96{ }^{\circ} \mathrm{C}$ for $10 \mathrm{~s}, 50{ }^{\circ} \mathrm{C}$ for $5 \mathrm{~s}$ and $60{ }^{\circ} \mathrm{C}$ for $4 \mathrm{~min}$, with a ramp rate of $1{ }^{\circ} \mathrm{C} / \mathrm{s}$ between each temperature.

Purification of sequencing reaction products was performed using Sephadex G-50 fine (GE Healthcare Life Sciences, Uppsala, Sweden) in 96-well multiscreen HV filter plates. After purification, the sequences were determined using an ABI-3130 Genetic Analyzer (Applied Biosystems, Carlsbad, CA, USA).

\section{Sequence editing and phylogenetic analysis}

A score was assigned to each nucleotide shown on the electropherogram for each sequencing reaction, using the online Phred application (available at http://asparagin.cen argen.embrapa.br/phph/). Only those positions with a
Phred index higher than 20 were used [22]. Nucleotides with a Phred index less than or equal to 20 were checked manually using Chromas software, v. 2.23 (1998-2002; Technelysium Pty Ltd., Australia) to identify interpretation errors and discrepancies between the sequences. The final sequence for each sample was obtained using CAP (contig assembly program) in BioEdit v. 5.0.9 [23] and submitted to the Nucleotide Basic Local Alignment Search Tool (BLASTn) for confirmation of sequence identity.

The DNA sequences that were obtained were aligned with a dataset of 89 homolog sequences of the $N$ gene obtained from GenBank using the multiple sequence alignment program CLUSTAL/W with the software MEGA7 [24], manually confirming the alignment for each group of sequences.

In order to perform genetic characterization and to verify the grouping of the RABV isolates in clusters with the 10 lineages known in Brazil, we compared our sequences to those available in the GenBank database, using the phylogenetic inference neighbor-joining (NJ) method with 1,000 bootstrap replications based on the Tamura-3 (T92) parameter model using a discrete gamma distribution $(+\mathrm{G})$ with five rate categories. The $\mathrm{T} 92+\mathrm{G}$ model was the best-fit substitution model considered under the Bayesian information criterion (BIC) and the corrected 
Akaike information criterion (AICc) in the model selection procedure processed in MEGA7 [24].

The applied methodology for the analysis of amino acid substitutions to the putative proteins of the gene studied was based on Lodish et al. [25] with the BioEdit v. 7.0.0 [23] program and using as reference the Pasteur Virus (PV) strain (GenBank accession number M13215). Amino acid substitutions in important regions of both proteins and the existence of amino acid substitutions specific to each bat genus was only performed with the sequences that grouped in the clusters representative of isolates from Brazilian insectivorous bats.

\section{Results}

\section{Antigenic characterization}

Antigenic characterization using a panel of MAbs revealed eight different antigenic profiles for the RABV isolates (Table 1), corresponding to the municipalities where the bats were found. The RABV isolates were grouped as follows: $36.8 \%$ (7/19) in variant $\mathrm{AgV}-3$, characteristic of the hematophagous bat Desmodus rotundus, six of which were isolated from frugivorous bats of the genus Artibeus two A. lituratus - and one isolated from an insectivorous bat of the genus Molossus; 5.3\% (1/19) in variant AgV-4, characteristic of the insectivorous bat Tadarida brasiliensis, which was identified in one insectivorous bat, Myotis spp.

However, six patterns of non-compatible (NC) results were identified when compared with profiles established using the panel of MAbs: NC1, which was identified in $21.0 \%(4 / 19)$ of RABV isolates and involved two bats of the genus Molossus, one Myotis and one A. lituratus; profile NC2, which was identified in $15.8 \%$ (3/19) of the samples, with isolates from three bats, A. lituratus, Myotis spp. and Myotis nigricans; and four other distinct profiles, $\mathrm{NC} 3, \mathrm{NC} 4, \mathrm{NC} 5$ and NC6, each of which was identified in one of the samples (5.3\% [1/19] each) in the genera of insectivorous bats Molossus (one), Nyctinomops (one) and Myotis (two; one of which belonged to the species Myotis nigricans).

\section{Molecular analysis, genotypic characterization and amino acid substitutions}

For the $N$ gene, a 499-nucleotide DNA fragment extending from nucleotides 209 to 709 , corresponding to amino acids 47 to 213 of the viral nucleoprotein (in relation to $\mathrm{PV}$ fixed virus), was obtained for 18 of 19 samples; only sample 063/2010 (Table 1) gave a negative result.
These 18 RT-PCR-positive isolates were sequenced after purification and quantification, and 16 of them revealed viable sequences after measurement with Phred and manual editing. Thus, in addition to sample 063/2010, samples 096/2007 and 205/2008 gave negative results.

In addition to the 16 DNA sequences determined here (GenBank accession numbers KX531062-KX531077), we used 89 sequences of RABV retrieved from GenBank to construct an NJ tree (Fig. 1). The tree showed the 10 lineages of RABV that are currently known in Brazil, seven of which are specific to insectivorous bats, and the other three are associated with the hematophagous bat D. rotundus, canids, and the marmoset Callithrix jacchus [6, 7, 26].

This genetic characterization enabled the grouping of 12 isolates into four previously known lineages: lineage $D$. rotundus Brazil in six frugivorous bats of the genus Artibeus and one insectivorous bat of the genus Molossus; lineage Nyctinomops Brazil in one Molossus and one A. lituratus; lineage Myotis Brazil in two insectivorous bats of the genus Myotis; and lineage Eptesicus Brazil in one Molossus. However, four RABV isolates formed a distinct cluster with a bootstrap value of $100 \%$. Two of them were isolated from bats of the genus Myotis, one from a bat of the genus Molossus, and one from a bat of the species $A$. lituratus.

Due to the inadequate size of the sequences generated, specific molecular markers for the lineages Myotis Brazil, Nyctinomops Brazil, and Eptesicus Brazil could not be identified. However, in the cDNA fragments studied, three specific amino acid changes were observed in the same four RABV isolates that formed this cluster distinct from the lineage Myotis Brazil (Table 4). Non-synonymous substitutions in these codons occurred at positions 79, 84 and 190 of the viral nucleoprotein.

\section{Discussion}

In Brazil, rabies is still considered an important zoonosis and a public health problem. In 2004, 22 cases of human rabies were registered in the country, and in 2005, there were 42 human cases [8]. From 1990 to 2001, domestic dogs were the main agents responsible for transmission in human rabies cases. Bats were responsible for the transmission of $14 \%$ of human rabies cases from 1990 to 1995 and $5.0 \%$ from 1996 to 2001, but their contribution grew to $63.8 \%$ from 2002 to 2009 , and they are now the main agent of rabies transmission to humans in Brazil [11].

Studies that provide genetic information on RABV are necessary, among other aspects, for tracing the origins of infections and developing effective control programs [27]. In this study, we analyzed $19 \mathrm{RABV}$ isolates from four different genera/species of non-hematophagous bats from 


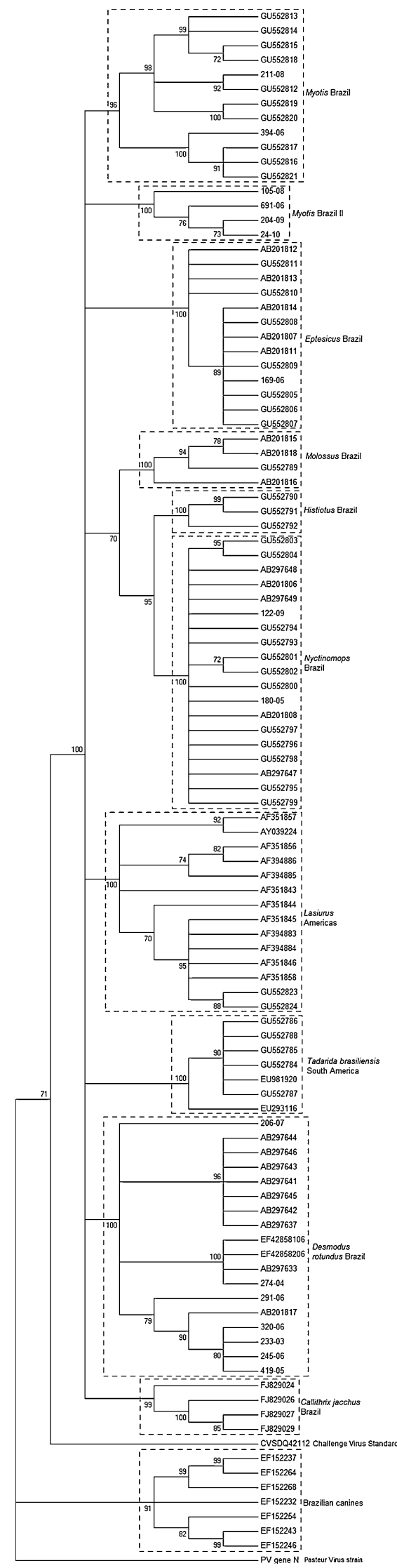

4Fig. 1 Condensed distance tree (with bootstrap values equal to or higher than 70) of partial nucleotide sequences of the rabies virus $N$ gene (nucleotides 209 to 709 ) of central nervous system isolates of non-hematophagous bats from five municipalities of São Paulo State, Brazil, constructed using the neighbor-joining algorithm and the evolution model MCL, with 1000 bootstrap repetitions. Values at each node represent the results of 1000 bootstrap repetitions. The identification number of each bat sample is shown

five municipalities in west-central São Paulo State. Their antigenic and genetic characterization enabled us to elucidate and evaluate the molecular epidemiology of RABV and the role of bats in virus distribution, which is a pioneering study in the area investigated.

Antigenic characterization showed interesting results, since the genera of the bats from which the RABV isolates were collected, Molossus, Artibeus, Nyctinomops and Myotis, had already been determined in previous studies conducted in other areas, which provided an important basis for the analysis in our study.

Eight different antigenic profiles were identified in the RABV isolates studied. Profile AgV-3, characteristic of the hematophagous bat $D$. rotundus, represented the largest group, which was identified in seven non-hematophagous bats (six Artibeus and one Molossus), a result that corroborates the findings of studies conducted in Brazil and Argentina [8, 28-31].

Numerous species of non-hematophagous bats of the most varied genera, contained isolates with the profile $\mathrm{AgV}-3$ of D. rotundus. One explanation for this observation could be the transmission of RABV between different species of bats, since up to 40 families of bats can share the same space. This supports the theory of virus transmission between different bat species [32]. This theory proposes that RABV variants and lineages circulate within a specific territory, which permits their identification because they are adapted and maintained by different animal species that are distributed regionally. This distribution can be altered if virus transmission from one primary host to a secondary host occurs (spillover). If this newly infected population maintains the infection for a long time, the distribution area where the virus is present is altered and may expand. An example of an important spillover event is the transmission of an RABV lineage from bats to carnivores, which occurred before the discovery of Americas and from which the RABV lineages of land animals originated [33].

A comparison of the antigenic results obtained in this study with the genetic characteristics of isolates with the AgV-3 profile, such as those of the D. rotundus Brazil lineage, suggest that RABV has undergone an interspecies jump. Likewise, an RABV isolate from an insectivorous bat of the genus Molossus was antigenically characterized as $\mathrm{AgV}-4$, which is a characteristic variant from the 
Table 4 Amino acid substitutions in the N protein of four rabies virus isolates probably belonging to an as yet undescribed lineage, here named Myotis Brazil II, using as reference the Pasteur virus (PV) strain (GenBank accession number M13215)

\begin{tabular}{llll}
\hline Position & PV & Substitution & Classification \\
\hline 79 & Q & Q (CAG) $\rightarrow$ N (AAT) & Q: polar neutral/N: polar neutral \\
84 & T & T (ACA $) \rightarrow$ I (ATA) & T: polar neutral/I: apolar \\
190 & T & T (ACT) $\rightarrow$ A (GCC) & T: polar neutral/A: apolar \\
\hline
\end{tabular}

insectivorous bat $T$. brasiliensis. In the genetic analysis, this isolate was grouped with the lineage Myotis, known as an RABV lineage from Brazilian insectivorous bats [6]. Six antigenic profiles were classified as non-compatible when analyzed using a panel of MAbs, totaling 11 isolates, and this result agrees with those of previous studies [6, 31, 34]. When the genotypic characteristics of isolates with these non-compatible profiles were analyzed, we observed that the $\mathrm{NC} 1$ profile was obtained with isolates that were classified as the genetic lineages Nyctinomops Brazil and Eptesicus Brazil. This profile has already been described for isolates of the lineage Eptesicus Brazil [35]. Based on these results, it is possible to infer that the NC1 profile is probably related to the genetic lineage Nyctinomops Brazil or Eptesicus Brazil. Further studies are necessary to confirm this supposition and to confirm the NC4 profile as specific to the lineage Nyctinomops Brazil.

One of two RABV isolates grouped in the genetic lineage Myotis Brazil showed the antigenic profile $\mathrm{AgV}-4$, which is also associated with the Tadarida Brasiliensis South America lineage [36]. The other isolate had the NC5 profile, and further studies are needed to determine whether it is a second specific antigenic profile for the Myotis Brazil lineage.

The NC2 antigenic profile was observed for three RABV isolates (one from Myotis, one from A. lituratus, and one from Myotis nigricans), all of which were genotypically assigned to a cluster that is distinct from the lineage Myotis Brazil, and here named "Myotis Brazil II". It is also possible that the NC2 and NC3 antigenic profiles represent specific patterns of reaction related to the Myotis Brazil II lineages when using the panel of MAbs. However, the observation of repetitions of this pattern in other isolates with the same genotypic characteristics, associated with the absence of this antigenic pattern in other strains, would be required to support this supposition.

Based on the results obtained, we can assume that the panel of MAbs provides only low resolution or does not permit a resolution as high as that obtained using genetic characterization, which may lead to divergences, as described previously. It is important to highlight that even though repetitions of an antigenic profile were observed compared with other studies from different regions, the same was not repeated in the genetic characterization after the same comparison [31].

Based on genotypic characteristics, the RABV isolates were grouped into four different previously described lineages [6]: Nyctinomops Brazil, Myotis Brazil, Eptesicus Brazil, and D. rotundus Brazil. It is worth highlighting that the groups were identified based only on the phylogenetic tree topography due to the size of the sequenced DNA fragment, which prevented us from identifying specific molecular markers for each lineage.

Our results demonstrate the circulation of four specific RABV lineages with distinct and independent epidemiological cycles, which were probably maintained by specific reservoirs that have already been described in the literature. An interesting fact when observing the bat species infected with these RABV lineages is that only the Myotis Brazil lineage was isolated from its natural reservoir, the insectivorous bat Myotis spp. These results support the theory that $\mathrm{RABV}$ is transmitted between different bat species.

As discussed previously, four RABV isolates grouped into a cluster that was distinct from the lineage Myotis Brazil, here named Myotis Brazil II, and this could represent an RABV lineage that is not yet known from Brazilian studies. Strong evidence of this new lineage is the genetic divergence of inter-cluster nucleotides of these four isolates in comparison to others present in the NJ tree, the maintenance of this cluster in the NJ tree constructed by the amino acid sequences (off-record data), and the existence of three amino acid substitutions that are fixed in these RABV isolates but absent in the others studied. Moreover, all of these isolates yielded non-compatible profiles in the antigenic analysis with panel of the MAbs.

Four RABV samples were isolated from two bats of the genus Myotis (one of which was $M$. nigricans), one from $A$. lituratus, and one from Molossus spp. Based on this, we presume that the reservoir of this lineage is probably bats of the genus Myotis, since A. lituratus bats and members of the genus Molossus are reservoirs of specific lineages; moreover, there are an apparently large number of bats of the genus Molossus that are infected with viruses of different lineages.

North American studies have already demonstrated the presence of two RABV lineages in the same area that were maintained by members of the same species of the genus 
Myotis, which shows that a single reservoir species can serve as a host for more than one adapted viral lineage [37].

The specific amino acid substitutions occurring in the $N$ protein of the putative new lineage, Myotis Brazil II, may indicate that natural selection had occurred with this viral phenotype, since amino acid alterations can result in phenotypic changes that affect the interaction of the virus with its habitat, which in this case is the host cell [38]. It is worth noting that there is a fine line between the viral phenotype and genotype distinction, since changes in the physical characteristics of the genome could themselves interfere with interactions between the virus and host molecules [39].

Surveillance actions are essential for identifying rabies virus reservoirs and potential new hosts [40]. A One Health approach that incorporates information on bats could be a promising strategy for rabies surveillance, which would benefit public health and wildlife because rabies is a wildlife-associated disease [41].

The results obtained here lead us to conclude that agreement between the antigenic characteristics, based on reactivity with MAbs directed against the viral nucleoprotein, and the genotype classification, based on partial sequencing of the $\mathrm{N}$ gene, was achieved with $37 \%$ (7/19) of the RABV isolates. Thus, we suggest a review of the panel of MAbs in order to update it and include new antigenic profiles that have been repeatedly reported in several Brazilian studies.

Based on the bat RABV isolates analyzed in the region studied, there are, in addition to the eight antigenic profiles, at least four circulating lineages, and strong evidence for the existence of a new lineage is presented here for the first time. These results extend our knowledge concerning the genetic variation of RABV in the Brazilian region studied and our current understanding of the circulation and transmission of RABV lineages in bat populations.

Acknowledgements This research received financial support of São Paulo Research Foundation (FAPESP, http://www.fapesp.br), grant no. 2015/07627-4. We gratefully acknowledge this financial support. The authors also acknowledge the researcher Maria Luiza Carrieri for her assistance in antigenic characterization, in addition to the staff of the Pasteur Institute and Zoonosis Diagnostic Laboratory of São Paulo State University.

Compliance with ethical standards The authors declare that they have no conflicts of interest (financial or non-financial). The research was conducted as part of the rabies diagnostic activities of the Zoonosis Diagnostic Laboratory of São Paulo State University (UNESP), Botucatu, São Paulo (public institution and accredited for official diagnosis of animal rabies) and epidemiological rabies surveillance activities in Brazil conducted by the reference center for the diagnosis of rabies, the Pasteur Institute, São Paulo, São Paulo State (public institution). There were no external sources of funding or participation of institutions other than those already mentioned. Regarding the animals (mice and bats) used in the research, the authors state that all the ethical and animal welfare requirements recommended by the National Council for Animal Experimentation Control (CONCEA) of the Brazilian Ministry of Science and Technology have been observed and fulfilled, and that approval was obtained from the Animal Experimentation Ethics Committee of Botucatu Medical School of UNESP, Botucatu, São Paulo, under protocol no. 762/2009, to perform all the procedures in this study.

Conflict of interest The authors declare that they have no conflicts of interest.

\section{References}

1. Brasil (2008) Manual de diagnóstico laboratorial da raiva, 1st edn. Editora do Ministério da Saúde, Brasília

2. Wunner HW (2007) Rabies virus. In: Jackson AC, Wunner HW (eds) Rabies, 2nd edn. Academic Press, San Diego, pp 23-68

3. ICTV IC on T of VVD-I ICTV Taxonomy History for Lyssavirus. http://www.ictvonline.org/taxonomyHistory.asp?taxnode_id= 20151092\&taxa_name=Lyssavirus. Accessed 2 Jun 2016

4. Velasco-Villa A, Gómez-Sierra M, Hernández-Rodríguez G et al (2002) Antigenic diversity and distribution of rabies virus in Mexico. J Clin Microbiol 40:951-958

5. Carnieli Junior P, Fahl WO, Castilho JG et al (2008) Characterization of Rabies virus isolated from canids and identification of the main wild canid host in Northeastern Brazil. Virus Res 131:33-46. doi:10.1016/j.virusres.2007.08.007

6. Oliveira RN, de Souza SP, Lobo RSV et al (2010) Rabies virus in insectivorous bats: implications of the diversity of the nucleoprotein and glycoprotein genes for molecular epidemiology. Virology 405:352-360. doi:10.1016/j.virol.2010.05.030

7. Favoretto SR, de Mattos CC, de Mattos CA et al (2013) The emergence of wildlife species as a source of human rabies infection in Brazil. Epidemiol Infect 141:1552-1561. doi:10. 1017/S0950268813000198

8. Kotait I, Carrieri ML, Carnieli Junior P et al (2007) Reservatórios silvestres do vírus da raiva: um desafio para a saúde pública. CTP, São Paulo

9. Langoni H, Cristina K, Menozzi BD, da Silva RC (2005) Rabies in the big fruit-eating bat Artibeus lituratus from Botucatu, Southeastern Brazil. J Venom Anim Toxins Incl Trop Dis 11:84-87

10. Kotait I, Carrieri ML, Takaoka NY (2003) Manejo de quirópteros em áreas urbanas. Instituto Pasteur, São Paulo

11. Brasil. Ministério da Saúde. Secretaria de Vigilância em Saúde. Departamento de Vigilância Epidemiológica (2011) Normas técnicas de profilaxia da raiva humana. Editora do Ministério da Saúde, Brasília

12. Ito M, Arai YT, Ito $U$ et al (2001) Genetic characterization and geographic distribution of rabies virus isolates in Brazil: identification of two reservoirs, dogs and vampire bats. Virology 284:214-222. doi:10.1006/viro.2000.0916

13. Baer AC (2007) The history of rabies. In: Jackson AC, Wunner HW (eds) rabies, 2nd edn. Academic Press, San Diego, pp 11-12

14. Schaefer R, Batista HBR, Franco AC et al (2005) Studies on antigenic and genomic properties of Brazilian rabies virus isolates. Vet Microbiol 107:161-170. doi:10.1016/j.vetmic.2005.01. 023

15. Vizotto LD, Taddei VA (1973) A chave para determinação de quirópteros brasileiros. Rev da Fac Filos Ciências e Let São José Rio Preto Bol Ciências 1:1-72

16. Gregorin R, Tadei VA (2002) Chave artificial para determinação de molossídeos brasileiros (Mammalia: Chiroptera). Mastozoología Neotrop 9:13-32 
17. Dean DJ, Abelseth MK, Atanasiu P (1996) The fluorescent antibody test. In: Meslin FX, Kaplan MM, Koprowski H (eds) Lab. Tech. rabies, 4th edn. World Health Organization, Geneva, pp 88-95

18. Koprowski H (1996) The mouse inoculation test. In: Meslin FX, Kaplan MM, Koprowski H (eds) Lab. Tech. rabies, 4th edn. World Health Organization, Geneva, pp 80-87

19. Diaz AM, Papo S, Rodriguez A, Smith JS (1994) Antigenic analysis of rabies-virus isolates from Latin America and the Caribbean. Zentralbl Vet B 41:153-160

20. Mattos, C; Mattos C (1998) Uso de anticuerpos monoclonales para la tipificación antigénica de aislamientos de virus rábico. In: OPAS OP de LS (ed) Consorc. la OPS Lab. Ref. en rabia las Américas, OPS. Whashington, DC, pp 2-11

21. Orciari LA, Niezgoda M, Hanlon CA et al (2001) Rapid clearance of SAG-2 rabies virus from dogs after oral vaccination. Vaccine 19:4511-4518

22. Ewing B, Green P (1998) Base-calling of automated sequencer traces using phred. II. Error probabilities. Genome Res 8:186-194

23. Hall TA (1999) BioEdit: a user-friendly biological sequence alignment editor and analysis program for Windows 95/98/NT. Nucleic Acids Symp Ser 41:95-98

24. Kumar S, Stecher G, Tamura K (2016) MEGA7: molecular evolutionary genetics analysis version 7.0 for bigger datasets. Mol Biol Evol 33:1870-1874. doi:10.1093/molbev/msw054

25. Lodish H, Berk A, Matsudaria P, et al (2005) Mecanismos básicos da genética molecular. In: Biol. Cel. e Mol. Artmed, Porto Alegre, p 119

26. Carnieli Junior P, Brandão PE, Carrieri ML et al (2006) Molecular epidemiology of rabies virus strains isolated from wild canids in Northeastern Brazil. Virus Res 120:113-120. doi:10. 1016/j.virusres.2006.02.007

27. Benjathummarak S, Fa-Ngoen C, Pipattanaboon C et al (2016) Molecular genetic characterization of rabies virus glycoprotein gene sequences from rabid dogs in Bangkok and neighboring provinces in Thailand, 2013-2014. Arch Virol 161:1261-1271. doi:10.1007/s00705-016-2789-8

28. Delpietro HA, Gury-Dhomen F, Larghi OP et al (1997) Monoclonal antibody characterization of rabies virus strains isolated in the River Plate Basin. Zentralbl Vet B 44:477-483

29. Albas A, Souza EAN, Lourenço RA et al (2009) Antigen profile of rabies virus isolated from different species of non-hematophagous bats in the region of Presidente Prudente, State of São Paulo. Rev Soc Bras Med Trop 42:15-17
30. Sodré MM, da Gama AR, de Almeida MF (2010) Updated list of bat species positive for rabies in Brazil. Rev Inst Med Trop Sao Paulo 52:75-81

31. Queiroz LH, Favoretto SR, Cunha EMS et al (2012) Rabies in southeast Brazil: a change in the epidemiological pattern. Arch Virol 157:93-105. doi:10.1007/s00705-011-1146-1

32. Macedo CI, Carnieli Junior P, Fahl WO et al (2010) Genetic characterization of rabies virus isolated from bovines and equines between 2007 and 2008, in the States of São Paulo and Minas Gerais. Rev Soc Bras Med Trop 43:116-120

33. Badrane H, Tordo N (2001) Host switching in Lyssavirus history from the Chiroptera to the Carnivora orders. J Virol 75:8096-8104

34. Almeida MF, Favoretto SR, Martorelli LFA et al (2011) Characterization of rabies virus isolated from a colony of Eptesicus furinalis bats in Brazil. Rev Inst Med Trop Sao Paulo 53:31-37

35. Favoretto SR, Carrieri ML, Cunha EMS et al (2002) Antigenic typing of Brazilian rabies virus samples isolated from animals and humans, 1989-2000. Rev Inst Med Trop Sao Paulo 44:91-95

36. Albas A, Campos ACA, Araujo DB et al (2011) Molecular characterization of rabies virus isolated from non-haematophagous bats in Brazil. Rev Soc Bras Med Trop 44:678-683

37. Streicker DG, Turmelle AS, Vonhof MJ et al (2010) Host phylogeny constrains cross-species emergence and establishment of rabies virus in bats. Science 329:676-679. doi:10.1126/science. 1188836

38. Borucki MK, Chen-Harris H, Lao V et al (2013) Ultra-deep sequencing of intra-host rabies virus populations during crossspecies transmission. PLoS Negl Trop Dis 7:e2555. doi:10.1371/ journal.pntd.0002555

39. Lauring AS, Acevedo A, Cooper SB, Andino R (2012) Codon usage determines the mutational robustness, evolutionary capacity, and virulence of an RNA virus. Cell Host Microbe 12:623-632. doi:10.1016/j.chom.2012.10.008

40. Picard-Meyer E, Robardet E, Moroz D et al (2012) Molecular epidemiology of rabies in Ukraine. Arch Virol 157:1689-1698. doi:10.1007/s00705-012-1351-6

41. Lu H, McComas KA, Buttke DE et al (2016) A one health message about bats increases intentions to follow public health guidance on bat rabies. PLoS One 11:e0156205. doi:10.1371/ journal.pone.0156205 